\title{
INDICADORES PSICOSSOCIAIS RELACIONADOS A ACIDENTES DE TRÂNSITO ENVOLVENDO MOTORISTAS DE ÔNIBUS ${ }^{1}$
}

\author{
Andréa Carla Ferreira de Oliveira* \\ José Q. Pinheiro"
}

\begin{abstract}
RESUMO. O objetivo do estudo foi identificar condições relacionadas a acidentes de trânsito envolvendo motoristas do transporte coletivo. Participaram 457 motoristas, todos do sexo masculino e empregados de companhias de ônibus de Natal, RN. O questionário empregado continha questões sobre atuação profissional, tais como: situações potencialmente preocupantes, efeitos das políticas das organizações empregadoras e características sociodemográficas, além do Inventário Zimbardo de Perspectiva Temporal e da Escala de Sonolência Epworth. As variáveis mais bem associadas ao envolvimento em acidentes foram: horas extras, trabalho em férias, emissão de atestados médicos, reclamações de passageiros, sonolência diurna excessiva e preocupação com: sono, dirigir atrasado e problemas familiares. A perspectiva temporal de presente não mostrou relação com envolvimento em acidentes. Conclui-se que o envolvimento de motoristas de ônibus em acidentes de trânsito pode ser evitado, ou ao menos diminuído, por meio de melhoria daquelas condições de trabalho e de políticas públicas de saúde e segurança pública.
\end{abstract}

Palavras-chave: acidente de trânsito, motorista de ônibus, condições de trabalho.

\section{PSYCHOLOGICAL AND SOCIAL INDICATORS ASSOCIATED TO TRAFFIC ACCIDENTS INVOLVING BUS DRIVERS}

\begin{abstract}
Psychological and social conditions potentially related to traffic accidents involving bus drivers are identified. Participants were 457 drivers, males and employees of local public transportation companies of Natal, RN, Brazil. Questionnaire contained items on professional performance comprising potentially stressing situations, effects of organizational policies and sociodemographic characteristics, in addition to Zimbardo Time Perspective Inventory and Epworth Sleepiness Scale. Variables highly associated to accident occurrences included extra work hours, work during vacations, medical leave, passengers' complaints, excessive daytime sleepiness, and concern about sleep, arriving late and family problems. Present time perspective was not related to involvement in accidents. Results suggest that involvement in traffic accidents may be avoided, or at least diminished, by an improvement in work conditions and through public policies of health and safety.
\end{abstract}

Key words: Traffic accidents, bus drivers, working conditions.

\section{INDICADORES PSICOSOCIALES RELACIONADOS A ACCIDENTES DE TRÁFICO ENVOLVIENDO CONDUCTORES DE ÓMNIBUS}

RESUMEN. El objetivo del estudio fue el de identificar condiciones relacionadas a accidentes de tráfico envolviendo conductores del transporte colectivo. Participaron 457 conductores, todos del sexo masculino y empleados de compañías de ómnibus de Natal, RN. El listado de la encuesta utilizado poseía cuestiones sobre actuación profesional, tales como: situaciones potencialmente preocupantes, efectos de las políticas de las organizaciones contratantes y características sociodemográficas, además del Inventario Zimbardo de Perspectiva Temporal y de la Escala de Somnolencia Epworth. Las variables más bien asociadas al envolvimiento en accidentes fueron: horas extras, trabajo en período de vacaciones, emisión de certificados médicos, reclamaciones de pasajeros, somnolencia diurna excesiva y preocupación con: sueño, conducir con retraso y problemas familiares. La perspectiva temporal de presente no mostró relación con envolvimiento en accidentes. Se concluyó que la incidencia del envolvimiento de conductores de ómnibus en accidentes de tráfico puede ser evitada, o al menos disminuida, por medio de mejorías de aquellas condiciones de trabajo y de políticas públicas de salud y seguridad pública.

Palabras-clave: accidente de tráfico, motorista de ómnibus, condiciones de trabajo.

\footnotetext{
Apoio: CAPES.

* Mestre em Psicologia pela Universidade Federal do Rio Grande do Norte. Professora da Faculdade de Natal-RN.

\# Doutor em Psicologia Ambiental pela Universidade do Arizona (Tucson, EUA). Professor Associado no Programa de Pós-graduação em Psicologia da Universidade Federal do Rio Grande do Norte.
} 
Se dirigir alguns minutos durante o dia para ir ao trabalho ou levar os filhos à escola pode ser um sofrimento para algumas pessoas, tendo-se em vista situações como engarrafamento na hora do rush e a ameaça constante da violência urbana, imagine-se ter o volante como ofício.

O trabalho dos motoristas profissionais no Brasil é caracterizado por ser rotineiro e por apresentar condições de trabalho inadequadas, ou seja, jornadas excessivas, noites mal-dormidas, hábitos alimentares inadequados e violência urbana (Fundação Joaquim Nabuco, 1982; Mendes, 1999; SEST, 2001). Um estudo realizado em 2000, pela Fundação SEADE, com 1762 motoristas de ônibus da região metropolitana de São Paulo, sobre as condições de saúde e segurança dos motoristas, revelou péssimas condições de trabalho, como: longos percursos, pausas para refeição muito curtas, precárias condições dos veículos, motoristas com mais de 10 horas diárias (22\%). Cavalcanti (1996) relata que os motoristas de ônibus são expostos diariamente a uma variedade de estressores ambientais, tais como: ruídos do motor, da porta e da buzina; iluminação inadequada; altas temperaturas; exposição a poluentes atmosféricos, principalmente provenientes de escapamentos de veículos (monóxido de carbono) e poeira (pó do asfalto); e o relacionamento com os passageiros e chefias, que muitas vezes passa a ser conflituoso, podendo levar a desequilíbrios psicoemocionais.

O Brasil, mesmo após o Novo Código de Trânsito, continua sendo reconhecido mundialmente por suas estatísticas de acidentes de trânsito, mortos e feridos (Lemes, 2003). As vítimas do trânsito vão desde os milhares de anônimos até personalidades famosas da nossa história. Mesmo assim, as estatísticas revelam apenas parcialmente o número real de acidentes no trânsito, pois se sabe como é difícil o registro de todos eles, haja vista que as autoridades de trânsito nem sempre são chamadas ao local, deixando de ser feito o boletim de ocorrência e ser contabilizado o acidente nas estatísticas oficiais. O Novo Código não promoveu ainda uma política e uma ação eficazes para intensificar a fiscalização e a promoção da cidadania no trânsito. Para Rozestraten (2003), a lombada eletrônica é um exemplo de distorção dos possíveis efeitos e benefícios idealizados, pois, apesar de ter provocado uma diminuição momentânea do excesso de velocidade, tem trazido, em contrapartida, um aumento de infrações e na indústria das multas.

O trânsito é vivido pelas pessoas no Brasil como uma apropriação privada de um espaço público. É comum percebermos isso na forma de dirigir das pessoas, as quais agem como se fossem donos das ruas. Estacionam carros nas calçadas, desrespeitam as faixas de pedestres, dirigem acima da velocidade permitida, provocando acidentes de trânsito, muitas vezes com vítimas fatais. Dirigir é um sinal de status, um símbolo de poder e sexualidade, um meio de expressar o individualismo e um instrumento para estabelecer independência (Zimbardo, Keough, \& Boyd, 1997). É importante destacar no cenário do trânsito o transporte coletivo, o qual é considerado pela Constituição Federal (Brasil,1998) como um dos serviços essenciais à população (Art. 30, V). Não obstante, o modelo atual do transporte urbano é inadequado à nossa sociedade, porquanto enfrentamos problemas como o crescimento desordenado das cidades, os danos ambientais causados por esse tipo de serviço, a qualidade do atendimento e eficiência da operação dos veículos muito aquém do esperado pela população, além da falta de incentivo do poder público ao setor (12ํㅡㄹ Congresso Nacional de Transporte e Trânsito, 1999). Os motoristas de ônibus e microônibus da cidade de Natal são os campeões em multas de trânsito. Segundo o Departamento Estadual de Trânsito, para cada grupo de 100 ônibus e microônibus são registradas 98,79 multas por ano (Tribuna do Norte, 2002).

É fato que qualquer acidente de trânsito - como fenômeno complexo que é - apresenta um conjunto de determinantes para sua ocorrência. Quando se fala nas condições dos motoristas profissionais do transporte público, podemos incluir entre elas a cultura vigente na organização, as políticas internas e as condições de trabalho, uma vez que aqueles condutores, no momento em que estão ao volante, além de cidadãos, também são empregados, com deveres e direitos. No Brasil, os motoristas são vistos como cidadãos únicos de direitos no trânsito, ou seja, como se o fato de estar dirigindo um automóvel os tornasse isentos de deveres e responsabilidades diante dos pedestres, da via e dos outros motoristas. O automóvel é visto como símbolo de poder e status - tem mais força quem tem o carro maior e mais potente. Para o pedestre sobra apenas submissão e intimidação, por ser considerado como menos importante, em razão da fragilidade que sua figura representa perante o "escudo de ferro" dos motoristas (Viecili, 2003).

$\mathrm{Na}$ realização desta pesquisa consideramos a literatura da área, em particular, o trabalho de Silva (1999), realizado com motoristas de ônibus de Brasília, sobre itinerário urbano, estressores ocupacionais e estratégias de enfrentamento. Esse autor observou que a preocupação em cumprir 
horários pode influir na presença de comportamentos inadequados dos motoristas no trânsito, como: parar fora do ponto, frear bruscamente, dirigir acima da velocidade permitida; indicando que o trânsito, enquanto evento característico de um itinerário urbano, pode afetar o desempenho desses profissionais.

Outra contribuição para este trabalho foi o estudo de Zimbardo, Keough e Boyd (1997), que verificaram que a perspectiva de tempo presente é um importante preditor do risco de dirigir. Para eles, o risco de dirigir inclui excesso de velocidade ao volante, a influência do álcool, a confiança irrestrita na habilidade de dirigir e estar voltado para a emoção do momento presente. Esse estudo utilizou o Inventário Zimbardo de Perspectiva Temporal (IZPT, ou Zimbardo Time Perspective Inventory, Zimbardo \& Boyd, 1999), o qual foi desenvolvido por Zimbardo e colaboradores ao longo de vários anos para estimar a perspectiva temporal, que pode ser definida como "a maneira com que os indivíduos e culturas repartem o fluxo da experiência humana em categorias temporais distintas de passado, presente e futuro" (Zimbardo \& cols., 1997, p. 1008). Assim, nossa expectativa neste estudo era encontrar a perspectiva de tempo presente mais destacada para os motoristas efetivamente envolvidos em acidentes.

$\mathrm{Na}$ elaboração do instrumento de pesquisa deste estudo foi considerada também a experiência da primeira autora no segmento local de transporte urbano por ônibus, assim como depoimentos de profissionais de recursos humanos do setor de tráfego e manutenção das empresas, fontes que se mostraram de extrema relevância para a tarefa.

Complementando o conjunto dos indicadores, incluímos a Escala de Sonolência de Epworth (Johns, 1991), com o objetivo de investigar a sonolência diurna excessiva em motoristas e observar se esta tinha relação com os acidentes de trânsito. A literatura médica mostra que a importância da sonolência diurna reside no fato de poder trazer prejuízos tanto para a qualidade geral de vida como para o desempenho de atividades profissionais ou à performance no trânsito (Canani \& Barreto, 2001).

Assim, o presente estudo teve por objetivo investigar indicadores potencialmente associados ao envolvimento de motoristas de ônibus urbanos em acidentes de trânsito. As variáveis preditoras agrupavam-se em torno dos seguintes tipos: situações potencialmente preocupantes; efeitos das políticas das organizações empregadoras; perspectiva temporal dominante nos motoristas; e sonolência excessiva diurna dos motoristas.

\section{MÉTODO}

\section{Participantes}

Tomaram parte no estudo 457 motoristas de 3 empresas do transporte público de passageiros da cidade de Natal, Rio Grande do Norte, todos do sexo masculino, com idade média de 39,6 anos $(D P=8,6$; idade mínima: 21; máxima: 77), sendo a maioria casada $(86 \%)$ e mais da metade $(62 \%)$ de baixa escolaridade (no máximo com $1^{\circ}$ grau completo). Esse grupo foi formado levando-se em conta a facilidade de acesso aos motoristas para aplicação do instrumento, e o critério de inclusão teve em vista lograrmos o maior número possível de respondentes entre os motoristas efetivamente ativos nas três empresas consideradas.

\section{Instrumento}

Foram elaboradas questões sobre características sociodemográficas e atuação profissional dos motoristas com base na literatura da área e por meio de entrevistas exploratórias com motoristas das empresas de transporte público de passageiros da cidade, além de registros feitos durante a experiência da primeira autora no setor. No mesmo questionário foram incluídos dois instrumentos já consolidados pela literatura internacional: Inventário Zimbardo de Perspectiva Temporal (IZPT) e Escala de Sonolência Epworth (ESE).

As questões referentes à atuação profissional tinham por objetivo investigar a percepção dos motoristas em relação às situações potencialmente estressantes enquanto dirigem o veículo. Para isso, solicitou-se aos participantes que assinalassem o grau de preocupação com cada tópico mencionado, devendo a resposta ser dada em escala tipo Likert de quatro níveis, variando de 0 (não preocupa) a 3 (preocupa muito). Questões relacionadas ao envolvimento em acidentes de trânsito e aos efeitos das políticas das organizações empregadoras também foram abordadas, incluindo temas como: hábito de atuar em horas extras, trabalho durante as férias, colocação de atestados médicos e reclamações de passageiros.

Empregamos todos os 56 itens da forma original do Inventário Zimbardo de Perspectiva Temporal (IZTP). Esses itens foram subdivididos em 5 escalas de perspectivas temporais: passado negativo, passado positivo, presente hedonístico, presente fatalístico e futuro. Apesar de cuidados como análise semântica preliminar das questões e aplicações-piloto a motoristas de ônibus de outras empresas, precisamos eliminar 20 itens daquele conjunto de 56, por razões como ambigüidade na compreensão de seu conteúdo, 
pouca ou nenhuma consistência interna (coeficiente Alfa, de Cronbach) de cada escala, e cargas fatoriais inferiores a 0,30 na análise executada (Oliveira, 2003). Essa nova estrutura do IZPT, com 36 itens, mostrou-se responsável pela explicação de $27 \%$ da variância total. No presente relato, apresentamos apenas os dados referentes à perspectiva temporal de presente, devido à expectativa já mencionada de vê-la relacionada ao envolvimento dos respectivos motoristas em acidentes de trânsito.

O questionário incluía ainda a Escala de Sonolência Epworth (ESE) -desenvolvida por Johns (1991), com o intuito de diagnosticar a ocorrência de sonolência diurna excessiva entre os respondentes. Ela foi aplicada apenas a um subgrupo de 112 motoristas, sem restrições ou critérios especiais de inclusão (ver seção Procedimento, a seguir). A escala é constituída de 8 situações associadas a diferentes possibilidades de cochilo e apresenta um enunciado bastante claro para diferenciar a situação de cansaço de sonolência, como ilustrado a seguir. "Gostaríamos de saber qual a possibilidade de o senhor cochilar ou mesmo dormir nas situações seguintes (não estamos falando de CANSAÇO e sim SONOLÊNCIA). Tais situações referem-se a seu modo de vida, em termos recentes. Ainda que não tenha passado por algumas dessas situações ultimamente, tente imaginar como o senhor teria agido." As situações apresentadas para avaliação da possibilidade de cochilar são do tipo: "Sentado tranquiilamente após o almoço, sem ingestão de bebida alcoólica". A escala varia de 0 (não cochilaria nunca) a 3 (grande chance de cochilar). Escores acima de 10 são considerados indicativos de sonolência diurna excessiva.

\section{Procedimento}

Cada empresa participante do estudo recebeu um ofício em que se solicitava permissão para coleta dos dados e se garantia sigilo das informações prestadas, bem como se firmava compromisso quanto à devolução dos resultados obtidos.

Foram realizadas 5 aplicações-piloto, as quais contribuíram bastante para o desenvolvimento da versão final do instrumento, tanto no tocante à linguagem das questões como quanto à redação da seção de instrução aos motoristas participantes do estudo, que visava a deixar claros os objetivos da pesquisa, o estabelecimento do rapport e a orientação sobre o correto uso do instrumento.

Os motoristas, convocados pelo serviço de psicologia das empresas, compareciam a sessões coletivas de aplicação do questionário, as quais ocorreram em salas de treinamento das próprias organizações, que atendiam aos critérios de iluminação e ventilação adequadas e ausência de ruídos. As sessões contaram com 2 aplicadores, alunos de graduação de um curso de Psicologia. O caráter voluntário da participação e a garantia do anonimato eram explicitamente enfatizados, assim como fazia parte das instruções que a anuência deles em participar do estudo seria considerada como seu consentimento livre e esclarecido.

Durante a tabulação dos dados nos demos conta da importância da informação sobre a preocupação com sono manifestada nas respostas dos motoristas. Como a coleta de dados ainda transcorria, optamos por aplicar a ESE a todos os motoristas que ainda iriam participar do estudo, razão pela qual o total de respondentes a essa escala foi de apenas 112 .

As análises estatísticas realizadas (testes $t$ e qui quadrado) tomaram como padrão para significância estatística o critério de probabilidade igual a cinco por cento, ou menor.

\section{RESULTADOS E DISCUSSÃO}

Dos 457 motoristas participantes do estudo, 252 (55\%) relataram ter-se envolvido em acidentes de trânsito no período de 1998 a 2002, quando questionados sobre esse assunto ( $\operatorname{sim} /$ não).

A seguir, apresentaremos as variáveis que se mostraram significativamente associadas ao envolvimento em acidentes, por blocos de indicadores, quais sejam: situações potencialmente preocupantes, efeitos das políticas das organizações empregadoras, perspectiva temporal e sonolência diurna excessiva.

\section{Situações potencialmente preocupantes}

Dos 30 indicadores de situações potencialmente preocupantes, observamos que 3 foram significativamente diferenciados (teste $t$ ), no sentido de mostrarem médias mais elevadas para os motoristas que se envolveram em acidentes de trânsito: preocupação em dirigir atrasado $(t=-2,654 ; g l=$ $384,973 ; p=0,008)$; preocupação com o sono $(t=-$ $3,187 ; g l=403,698 ; p=0,002)$ e preocupação com problemas familiares $(t=-2,123 ; g l=433,073 ; p<$ 0,034).

Dirigir atrasado pode ser visto como gerador de estresse e favorece maior dispersão da atenção do condutor com situações ocorridas em seu entorno mais imediato (o ônibus) e com o trânsito, podendo levar a comportamentos indesejáveis ao lidar com essas situações à diminuição de suas condições de reagir às demandas específicas da condução do veículo no 
trânsito. Esse dado confirma o estudo de Silva (1999), o qual classifica como comportamentos inadequados no trânsito frear bruscamente, parar fora do ponto do ônibus, dirigir acima da velocidade permitida e fazer ultrapassagens perigosas por causa de atrasos nas viagens dos condutores.

Quanto à preocupação com o sono, nossos resultados ratificam estudos anteriores, pois é notória a incidência de estatísticas de acidentes de trânsito envolvendo motoristas que dormiram ao volante. Para Melo, Santos e Tufik (2001), faz-se necessário observar de forma detalhada as escalas de trabalho dos motoristas profissionais e dos trabalhadores em turno para uma melhor adequação do ritmo biológico e o cronotipo dos indivíduos ao trabalho que desenvolvem. Tal adequação faz reduzirem-se os custos operacionais das empresas, aumenta a qualidade de vida do trabalhador e reduz a incidência dos distúrbios do sono.

É importante considerar o cenário organizacional, com suas políticas de pessoal, muitas vezes, incentivadoras de situações potencialmente estressantes, como o estímulo das empresas de transportes à prática diária de horas extras. Para as organizações, horas extras representam uma forma de evitar novas contratações e, conseqüentemente, reduzir os encargos trabalhistas, enquanto para os motoristas constituem a possibilidade de ter uma renda adicional ao seu salário-base. Se entre os motoristas há aqueles que buscam a prática das horas extras, também há os que as abominam, por perceberem-nas como prejudiciais à saúde e/ou por elas comprometerem sua relação com familiares e amigos - tendo em vista a ausência prolongada do lar -, além de geradoras de cansaço, sonolência durante o trabalho, dores de cabeça e mal-estar. Não obstante, o que pensar dos motoristas que apresentam preocupação com o sono e dos que se envolvem em acidentes de trânsito diante de práticas organizacionais incentivadoras de jornadas excessivas, mesmo quando existe um acordo coletivo da categoria determinando, no caso dos motoristas estudados, 7 horas e 20 minutos?. Atribuir a responsabilidade pelo acidente apenas ao motorista de transporte coletivo pode ser injusto diante de tantas nuanças da organização e do cenário do trânsito.

No tocante à preocupação com problemas familiares, fica claro que esses motoristas com história de acidentes de trânsito também estariam psicologicamente removidos da situação imediata de seu posto de trabalho, submetidos que estão a tais pressões que afetam seu desempenho como condutores profissionais. Para Almeida (2002), problemas familiares estão inseridos na categoria de problemas pessoais, assim como brigas, dívidas, perdas materiais, morte e outros. Se dirigir sem qualquer preocupação já requer atenção e cuidados com as condições do veículo e da via e com os outros motoristas, o que pensar de conduzir um veículo horas a fio preocupado com problemas familiares? Com base na experiência de psicólogos do setor de transportes, sabemos que esses problemas podem incluir: problemas escolares dos filhos, dívidas em atraso, separação conjugal, outras companheiras além da esposa, filhos de relação extraconjugal, problemas de saúde com esposa e/ou filhos, entre outros, os quais, sem dúvida, afetam o equilíbrio psicológico dos motoristas e os predispõem ao envolvimento em acidentes de trânsito. Não obstante, mais uma vez se faz necessário considerar o contexto da organização, com suas políticas de pessoal, procurando questionar o papel dessas políticas no que diz respeito ao acompanhamento psicológico desses profissionais do volante, que têm como responsabilidade transportar diariamente centenas de pessoas. As empresas que mantêm psicólogos em seu quadro de pessoal têm uma grande demanda de recrutamento e seleção de pessoal, dificultando um atendimento psicológico mais voltado para uma ação preventiva de acidentes.

\section{Efeitos das políticas das organizações empregadoras}

Investigamos a possível influência sobre o envolvimento de motoristas em acidentes de trânsito de práticas e realidades vivenciadas pelos próprios motoristas em decorrência das políticas das empresas empregadoras, tais como cumprir horas extras, participar em treinamentos, ter reclamações de passageiros, trabalhar durante as férias, apresentar atestados médicos, entre outras.

As jornadas excessivas de trabalho foram caracterizadas neste estudo pela horas extra se pelo trabalho dos motoristas durante suas férias. Verificamos uma diferença estatisticamente significativa (teste $t$ ) entre o número médio de horas extras (ao mês) dos que se envolvem em acidentes (13,04 horas) e a média praticada pelos que não se envolvem em acidentes (8,8 horas; $t=-2,708 ; g l=$ 422,435; $p=0,007)$. A diferença encontrada não surpreende, uma vez que quanto mais tempo o motorista passa no trânsito, maior é o cansaço, o estresse e a possibilidade de se envolver em acidentes. Como aponta Câmara (2002): "mais da metade dos acidentes ocorreu no final da jornada de trabalho ou enquanto os motoristas 'dobravam' sua jornada de trabalho". 
Ao mesmo tempo, $61 \%$ dos participantes responderam sim à questão sobre trabalhar durante as férias, o que resultou em associação significativa desse fato com envolvimento em acidentes de trânsito $\left(\chi^{2}=\right.$ $5,83 ; p \leq 0,016)$. Gozar as férias deveria ser para o trabalhador uma ocasião de descanso, lazer e desligamento da rotina de trabalho. Se ele não o faz e, ao contrário, continua trabalhando, é de se esperar que ele esteja mais vulnerável a ocorrências como acidentes de trabalho.

Não é somente o desempenho laboral do condutor que é afetado por trabalhar horas a mais do que sua jornada de trabalho ou durante as férias. Sua saúde também é afetada, a julgar pelos 179 motoristas (39\%) que afirmaram ter apresentado atestados médicos durante o ano anterior. Verifica-se que na maioria das empresas de transporte coletivo as condições de trabalho oferecidas são precárias, a começar pela ergonomia: os bancos dos motoristas não são reguláveis; o tempo de descanso não é observado, devido aos atrasos das viagens; a alimentação é prestada por empresas terceirizadas, as quais nem sempre dispõem de nutricionistas para elaboração das dietas dos condutores; algumas empresas não apresentam instalações sanitárias nem espaço adequado para descanso, favorecendo o aparecimento de doenças e consequientemente a "colocação" de atestados médicos pelos condutores.

Receber reclamações de passageiros pode ser compreendido como um indicador do mau desempenho do motorista no trânsito, o que, para Silva (1999), revela-se através dos comportamentos inadequados no trânsito. Em nosso estudo, as reclamações de passageiros também se associaram positivamente ao envolvimento em acidentes de trânsito $\left(\chi^{2}=6,714 ; g l=\right.$ $1 ; p \leq 0,01)$, o que permite apontá-las como indicadores indiretos do desempenho do condutor e como orientação para a implantação de políticas de acompanhamento e prevenção de acidentes. Desse modo, incluir a perspectiva dos usuários na administração desse tipo de serviço talvez seja uma forma de obter melhorias dos serviços prestados à população.

\section{Perspectiva temporal como preditora de acidentes de trânsito}

Com base nos estudos da equipe de Zimbardo sobre perspectiva temporal e, mais particularmente, na investigação que relacionou a perspectiva temporal de presente com o risco de dirigir (Zimbardo, Keough, \& Boyd, 1997), esperávamos encontrar uma relação positiva entre o envolvimento em acidentes e o fato de as pessoas estarem mais voltados para o presente, segundo o IZPT.

Diante da inexistência de estudos com esse instrumento na realidade de nosso país, procedemos à sua análise fatorial completa (Oliveira, 2003). Para os fins desta comunicação, no entanto, importa mencionar que, apesar de nos estudos originais de Zimbardo e colaboradores terem sido identificados dois tipos de presente, o hedonístico e o fatalístico (Zimbardo \& Boyd, 1999; Zimbardo, Keough, \& Boyd, 1997), as respostas dos motoristas participantes desta investigação geraram um único presente, a que denominamos presente combinado.

Comparamos, então, as médias do escore fatorial desse presente combinado para motoristas envolvidos ou não em acidentes. Para os 203 motoristas que não se haviam envolvido em acidentes a média de presente combinado foi - 0,09 $(D P=1,01)$, e para os 254 motoristas que haviam se envolvido em acidentes de trânsito a média foi $+0,07(D P=0,98)$. A diferença observada foi na direção teoricamente esperada, mas o nível de significância estatística associado apenas se aproximou do critério estabelecido de probabilidade igual a cinco por cento, ou menor $(t=-1,682 ; g l=$ 426,834; $p \leq 0,09)$.

A interpretação desse resultado considera dois aspectos: a) a variável critério, no presente estudo, envolveu uma informação "real" sobre os acidentes em que o respondente tinha se envolvido (ou próxima da verdadeira situação de cada motorista, pois o questionário continha outras questões verificáveis de controle sobre esse dado, como número de multas no ano anterior), e não o "risco de dirigir", como nos autorelatos dos estudos originais; b) as escalas "presente hedonístico" e "presente fatalístico", definidas separadamente nos estudos originais com estudantes de importantes universidades estadunidenses, juntaram-se em um mesmo componente em nossa análise (presente combinado). Nossa proposição de um presente combinado foi fruto direto da análise fatorial, mas também da compreensão de que para os motoristas brasileiros a idéia de presente possivelmente seja única, resultante das diferenças socioeconômicas envolvidas em uma hierarquia de necessidades dos participantes, primordialmente relacionadas à sobrevivência imediata, própria e de familiares.

\section{Sonolência diurna excessiva}

Dentre os 112 respondentes da Escala de Sonolência Excessiva (ESE), 32 atingiram 11 ou mais pontos, o que é considerado como sonolência excessiva diurna (Johns, 1991). 
Na questão sobre a preocupação que eles têm com o sono ao conduzir, a média dos 112 respondentes foi $1,58(D P=1,35)$, praticamente o ponto médio da escala likert, que variava de zero a três. Entretanto, os 32 motoristas com sonolência diurna excessiva devem ter alguma consciência do próprio problema, pois, ao considerarmos o coeficiente de correlação entre a ESE e a preocupação com o sono, esse indicador de autopercepção do problema chega a 20\% $(r=0,196 ; p$ $\leq 0,039 ; N=112$ ). Como se pode observar na Tabela 1, a diferença mais pronunciada de média na ESE para os quatro níveis de preocupação com sono se verifica entre os que não se preocupam e os demais. As diferenças são significativas entre os níveis 0 e $1(t=$ $2,611 ; g l=13,401 ; p \leq 0,021)$ e entre 0 e $3(t=-2,191$; $g l=84,850 ; p \leq 0,031)$.

Tabela 1. Médias da Escala de Sonolência Excessiva para os Quatro Níveis de Preocupação com Sono

\begin{tabular}{ccccc}
\hline \multirow{2}{*}{ Níveis de preocupação com o sono } & \multicolumn{3}{c}{ Escala de Sonolência Excessiva } \\
\cline { 2 - 4 } & $\mathrm{N}$ & Média & $D P$ \\
\hline 0 & 42 & 7,36 & 3,681 \\
1 & 8 & 10,13 & 2,532 \\
2 & 17 & 8,76 & 3,717 \\
3 & 45 & 9,11 & 3,785 \\
\hline
\end{tabular}

Ao mesmo tempo, 72 respondentes (64\%) afirmaram manter a prática de horas extras. A média desses respondentes na ESE foi mais alta $(M=8,93)$ do que a média dos que não praticam horas extras $(M=$ 7,$65 ; N=40$ ), um resultado que chegou próximo de atingir significância estatística $(t=-1,733 ; g l=$ 77,605; $p \leq 0,087$ ) e que mais uma vez aponta para importantes aspectos das condições de trabalho dos motoristas estudados. Possivelmente, esses dados sinalizam que de fato a política das horas extras adotada por algumas empresas evita novas contratações de pessoal, mas também passa a ter como conseqüências das jornadas prolongadas o cansaço, o estresse e a sonolência excessiva, afetando diretamente a saúde do condutor e as condições de segurança na via.

Em relação a envolver-se em acidentes de trânsito, foram $59(53 \%)$ os motoristas a responder afirmativamente, cuja média na ESE foi 9,05. Como seria de esperar, tal média é mais elevada do que a dos participantes que informaram não ter se envolvido em acidentes $(M=7,83 ; t=-1,746 ; g l=109,062 ; p \leq$ $0,084)$, confirmando as informações apresentadas em estudos que relacionam acidentes na condução de veículos com a sonolência excessiva do condutor (e.g., Canani \& Barreto, 2001).
Apesar de apresentarem nível de significância estatística ligeiramente insatisfatório, os indicadores relativos a horas extras e a acidentes sugerem forte relação com a sonolência excessiva. Tal fato seria percebido pelos próprios motoristas, que se preocupam com o fato, mostrando a importância de se investigarem as condições laborais desses trabalhadores, principalmente o fato de estarem expostos a escalas rígidas de trabalho, as jornadas excessivas e a indiferença da grande maioria das empresas quanto à necessidade de ajustar o relógio biológico dos condutores aos turnos de trabalho.

\section{CONSIDERAÇÕES FINAIS}

No que diz respeito aos indicadores relativos a situações potencialmente preocupantes, verificou-se que dirigir atrasado, preocupações com o sono e problemas familiares foram as situações que mais se destacaram em relação ao envolvimento dos motoristas participantes deste estudo em acidentes de trânsito

Em relação aos efeitos das políticas das organizações empregadoras, destacaram-se jornadas excessivas de trabalho - seja através das horas extras diárias seja através de trabalho durante as férias -, reclamações de passageiros e "colocação" de atestados médicos. Esses indicadores sinalizam uma relação, ainda que não necessariamente direta, entre as condições de trabalho, o desempenho do motorista no trânsito e sua saúde, repercutindo no envolvimento em acidentes de trânsito.

Quanto ao conceito de perspectiva temporal, a escala presente combinado mostrou uma tendência na direção teoricamente esperada (de uma relação positiva com envolvimento em acidentes de trânsito), ainda que a diferença de médias registrada não tivesse atingido significância estatística. As dificuldades instrumentais encontradas na utilização do Inventário Zimbardo de Perspectiva Temporal (IZPT) com uma população cultural e economicamente distinta da envolvida nos estudos originais sugere a necessidade de estudos adicionais, uma vez que as implicações do conceito básico pareceram promissoras para a compreensão dos fenômenos estudados.

Em relação à sonolência diurna excessiva, os resultados sinalizam a necessidade de uma maior investigação das possíveis causas relacionadas ao déficit de sono dos motoristas, o qual pode estar mascarado nessa resposta, assim como o risco para a saúde do trabalhador e o comprometimento das suas habilidades físico-motoras no trabalho e da segurança 
das pessoas que fazem uso do transporte coletivo diariamente.

Sugere-se às empresas do setor de transporte público de passageiros uma reavaliação das políticas, de forma a reduzir o número de horas extras, respeitando a jornada estabelecida no acordo coletivo da categoria, e estimular o gozo integral das férias dos condutores como uma maneira de aliviar o estresse e aumentar a qualidade do trabalho e de vida. Compreender os acidentes através de seus multideterminantes é de fundamental importância para que cada personagem do processo (motorista, pedestre, empresário, governo) possa desempenhar seu papel na luta por um trânsito mais seguro e pela preservação da vida humana.

\section{REFERÊNCIAS}

12º Congresso Nacional de Transporte e Trânsito (1999). Os grandes desafios do transporte urbano. Disponível em: <http:// www.antp.org.br>. (Acesso em 05/05/2001).

Almeida, N. D. V. (2002). Comtemporaneidade x trânsito: reflexão psicossocial do trabalho dos motoristas de coletivo urbano. Psicologia, Ciência e Profissão, 22(3), 62-69.

Brasil (1998). Constituição Federal do Brasil. São Paulo: Revista dos Tribunais. (Original publicado em 1988).

Canani, S. F. \& Barreto, S. S. M. (2001). Sonolência e acidentes automobilísticos. Jornal de Pneumologia, 27(2), 94-96.

Câmara, P. (2002). O risco de acidentes entre motoristas profissionais em função do estresse e fadiga. Revista Abramet. Disponível em: < www. redetran.com.br>. (Acesso em 20/06/2002).

Cavalcanti, V. L. (1996). Subsídios técnicos que justifiquem a manutenção da aposentadoria especial para motoristas de ônibus urbano. São Paulo. (texto não-publicado)

Fundação Joaquim Nabuco (1982). O motorista de ônibus da região metropolitana do Recife: suas condições de vida e trabalho (Relatório de pesquisa). Recife: Instituto de Pesquisa Sociais da UFPE.

Fundação SEADE - FUNDACENTRO (2001). Cotidiano problemático: motoristas urbanos. Revista Proteção, 117, 3250.

Johns, M. W. (1991). A new method for measuring daytime sleepiness: The Epworth Sleepiness Scale. Sleep, 14, 540-545.
Lemes, E. C. (2003). Trânsito e comunidade: um estudo prospectivo na busca pela redução de acidentes. Em M. H. Hoffamann, R. M. Cruz \& J. C. Alchieri (Orgs.), Comportamento humano no trânsito (pp. 137-151). São Paulo: Casa do Psicólogo.

Melo, M. T., Santos, E. H. \& Tufik, S. (2001). Acidentes automobilísticos, direção e sonolência excessiva: ergonomia e qualidade de vida no setor de transportes (pp. 7-30). Brasília: Confederação Nacional do Transporte.

Mendes, L. R. (1999). O trabalho do motorista de ônibus: reflexões sobre as condições de trabalho no transporte coletivo. Em J. R. Sampaio (Org.), Qualidade de vida, saúde mental e Psicologia Social (pp. 153-180). São Paulo: Casa do Psicólogo.

Oliveira, A. C. F. (2003). Indicadores associados a acidentes de trânsito envolvendo motoristas de ônibus da cidade de Natal. Dissertação de mestrado Não-Publicada, Universidade Federal do Rio Grande do Norte, Natal.

Rozestraten, J. A. (2003). Ambiente, trânsito e Psicologia. Em M. H. Hoffamann, R. M. Cruz \& J. C. Alchieri (Orgs.), Comportamento humano no trânsito (pp. 33-43). São Paulo: Casa do Psicólogo.

SEST-Serviço Social do Transporte \& SENAT- Serviço Nacional de Aprendizagem do Transporte (2001). Ergonomia $e$ qualidade de vida no setor de transporte. Brasília: Serviço Social do Transporte (SEST)/ Serviço Nacional de Aprendizagem do Transporte (SENAT).

Silva, A. V. (1999). Comportamentos de motoristas de ônibus: itinerário urbano, estressores ocupacionais e estratégias de enfrentamento. Dissertação de mestrado Não-Publicada, Universidade de Brasília, Brasília.

Tribuna do Norte (2002). Ônibus e microônibus lideram multas. Disponível em: < www.tribunadonorte.com.br>. (Acesso em 08/05/ 2002).

Viecili, J. (2003). Ansiedade e comportamento de dirigir. Em M. H. Hoffamann, R. M. Cruz \& J. C. Alchieri (Orgs.), Comportamento humano no trânsito (pp. 359-374). São Paulo: Casa do Psicólogo.

Zimbardo, P. G., Keough, K. A. \& Boyd, J. N. (1997). Present time perspective as a predictor of risky driving. Journal of Personality and Individual Differences, 23(6), 1007-1023.

Zimbardo, P. G. \& Boyd, J. N. (1999). Putting time in perspective: A valid, reliable individual-differences metric. Journal of Personality and Social Psichology, 77(6), 1271-1288.

Recebido em 17/11/2005 Aceito em 27/04/2006

Endereço para correspondência: Andréa Carla Ferreira de Oliveira. Avenida Alameda das Mansões, 2110, Candelária, CEP 59064-740, Natal-RN. E-mail: acarla@cefetrn.br 